(RESEARCH ARTICLE)

\title{
Allium tuberosum aqueous extract had curative effects on malignant melanoma in C57BL/6 mice
}

Corvaia-Bolívar María Carolina, González-Barrios Andrea Carolina, Colmenárez-Rojas Arlyne Alexandra, Pulido-Barreras Silvana Paola, Suárez-Rodríguez Marian Andrea and Bonfante-Cabarcas Rafael Armando *

Biochemistry Research Unit, Health Science School, Universidad Centroccidental "Lisandro Alvarado", Av Libertador/Andres Bello, PC: 3001, Barquisimeto, Venezuela.

Publication history: Received on 07 June 2020; revised on 01 July 2020; accepted on 03 July 2020

Article DOI: https://doi.org/10.30574/wjarr.2020.7.1.0191

\begin{abstract}
Cancer is still a disappointing public health problem worldwide; in this context medicinal plants could be visualized as a promising alternative for antitumor adjuvant therapy. Here the effect of Allium tuberosum (AT) aqueous extract on the evolution of B16F10 melanoma in C57BL/6 mice and on melanoma cells in vitro anaerobic metabolism were studied. 33 mice were divided in 4 groups: control melanoma (CM; n=7), AT given orally (AT0; $\mathrm{n}=9$ ), $A T$ and celecoxib given orally (ATCxO; $\mathrm{n}=7$ ) and $A T$ given orally and intratumorally (ATOI; n=10), to which 200,000 tumor cells were transplanted into the right leg hind paw. Clinical and pathological signs of malignant melanoma disease progression were evaluated in vivo, while anaerobic glycolysis and redox capacity using methylene blue were measured in vitro. AT aqueous extract were given therapeutically from the time of tumor onset. Results shown that ATO groups displayed longer survival time with decreased tumor growth, while ATOI group no tumor macroscopic infiltration and islands of degenerating extensive necrotic melanoma cells infiltrated by mononuclear cells and fibrosis were observed. In vitro, $A T$ extract decreased anaerobic metabolism in a dose-dependent manner ( $\mathrm{IC}_{50}=1.13 \mathrm{mg} / \mathrm{ml}$ ) and ATO tumor cells had a greater reductive capacity. In conclusion, $A T$ had a cytotoxic curative effect on melanoma B16F10 in C57BL/6 mice related with a decreased anaerobic metabolism and increased redox capacity of cancer cells, indicating that $A T$ counteracts Warburg's effect favouring aerobic metabolism.
\end{abstract}

Keywords: Allium tuberosum; Melanoma; Cancer; C57BL/6; B16F10; Anaerobic Metabolism; Warburg's effect.

\section{Introduction}

According to the World Health Organization (WHO), cancer represents the second leading cause of death worldwide after cardiovascular diseases and continues to grow globally, generating enormous physical, emotional and financial wear on patients, their families and in health systems. Unfortunately, health systems in low-income countries are generally less prepared to handle cancer; as a result, a large number of cancer patients do not have access to an adequate diagnosis or treatment, leading to avoidable suffering and deaths. Approximately $70 \%$ of cancer deaths occur in low and middle-income countries [WHO/consulted December 2019/https://www.who.int/cancer/PRGlobocanFinal.Pdf].

Melanoma is a melanocyte malignant skin cancer, which develops when unrepaired DNA damage caused mostly by ultraviolet radiation, triggers mutations that lead to cell carcinogenesis [1]. In research, the most used malignant melanoma cell line is B16F10, which readily growths in C57BL/6 mice, being a useful model for tumour formation and metastasis studies [2].

Malignant melanoma is the most lethal form of skin cancer. The incidence of melanoma is growing more rapidly than nearly all other cancers. In 2012 incidence were estimated at 76,250 cases and it has been rising up steadily for the past 30 years, with a $3 \%$ increase each year. This growth in incidence lead to a rising burden to society, becoming the fifth

* Corresponding author: Bonfante-Cabarcas Rafael Armando, phone: +56920243041, e-mail: rbonfantecabarcas@gmail.com 
most common malignancy in men, and sixth most common in women [3]. Treatment is based on surgery, chemotherapy, immunotherapy and radiotherapy. The most challenging concern in chemotherapy is its low selectivity, which implies a high percentage of healthy cells loss, with functional repercussions. Therefore, new adjuvant complementary therapeutic protocols should be explored with the aim of improving cure rates, quality of life and survival [1].

Plant-derived agents have played a vital role in the treatment of cancer. Over 3,000 species that possess anti-cancer properties have been reported, and more than $60 \%$ of currently used anti-cancer agents are derived from these natural sources. Many herbs have been evaluated in clinical studies and they are currently being investigated to understand their tumoricidal properties against various cancers, and some have shown promising results $[4,5]$.

Medicinal plants of the Allium genus are interesting alternatives for cancer treatment, including garlic, onion, leek, chives and shallot. Phytochemical analysis of compounds with anticancer properties obtained from these plants have shown various organic and sulphur compounds, such as S-allyl mercaptocysteine, quercetin, flavonoids and ajoene. These compounds interfere with various stages involved in the formation, growth, differentiation and metastasis of cancer cells [6].

Like garlic and onions, other species of the genus could exhibit anti-cancer activities. For instance, Allium tuberosum (AT) (traditionally called garlic chives, Oriental garlic, Asian chives, Chinese chives or Chinese leek) is a perennial plant with garlic like flavour and very strong odour due to its sulphur-containing compounds, like sulphides and thiosulfinates. Their leaves and inflorescences are an important ingredient in many European and Asian cuisine. It is used for treatment of abdominal pain, diarrhoea, hematemesis, snakebite, and asthma. Its crude extracts have antimicrobial properties against various bacteria, fungi and antioxidant activities [7].

Few studies have been done about $A T$ effects on cancer models, most of them tested in vitro effects of thiosulfinates purified from chives [8,9,10], others used fresh aqueous buffered extract [11] or purified protein [12]. Thus, thiosulfinates inhibited cell proliferation in vitro by activating apoptotic pathways in colon, prostate and human cancer cells, as well as in sarcoma murine cells $[8,9,10]$; tested in vivo they increased life spans of mice inoculated with sarcoma180 cancer cells [10]. Likewise, Chitinase like $36 \mathrm{kD}$ protein, isolated from chives exerted some cytotoxic effect in vitro on breast cancer cells [12]. Similarly, fresh AT phosphate-buffered saline extract inhibited growth of murine and human cancer cell lines in vitro [11].

On the other hand, in vivo treatment with a daily oral extract ( 2.5 or $12.5 \mathrm{mg} / \mathrm{gr}$ ) reduced B16F10 melanoma lung metastatic colonies in C57BL/6 mice by $40 \%$. However, intravenous injection of the extract (1.25 or $6.25 \mathrm{mg} / \mathrm{gr}$ ) did not show any effect [11], even when doses could have been higher, creating controversy over whether these results were really a consequence of the primary components found in AT.

Since experimental bibliographic data on the role of $A T$ on the evolution of cancer in animal models are scarce and contradictory, in the present paper we have done a progressive clinical pathological study of malignant B16F10 melanoma in C57BL/ 6 mice. This animal model allowed us to evaluate gradually the progression of the disease; similar to what it happens in humans, in order to visualize in more detail the therapeutic effect of $A T$ aqueous extracts. The objective was to determine the effect of $A T$ aqueous extract on the evolution of malignant melanoma with the aim to demonstrate that $A T$ has curative effect against B16F10 malignant melanoma in C57BL/6 mice.

\section{Methods}

\subsection{Sample}

33 C57BL/6 male mice, weighting 15 to 20 gr, were obtained from animal facilities at the Universidad Centroccidental "Lisandro Alvarado" (Barquisimeto, Venezuela). 7 to 10 mice were put in 32.5 x 33.5 x $13.5 \mathrm{~cm}$ stainless steel cages with free access to potable water and pelleted animal food, 12 hours day/night cycles, with a $27^{\circ} \mathrm{C}$ average temperature. Mice were randomly divided initially in three experimental groups: Control Melanoma ( $\mathrm{n}=7 ; \mathrm{CM}), A T$ given orally ( $\mathrm{n}=9$; ATO) and $A T$-Celecoxib given orally ( $\mathrm{n}=7$; ATCxO). Additionally, later with the aim to confirm primary clinical results, 10 mice were included and received both oral and intratumoral $A T$ treatment (ATOI).

\subsection{Melanoma Xenograft}

Mice were transplanted with 200,000 Bl6-F10 malignant melanoma cells in $50 \mu \mathrm{L}$ of MEM, subcutaneously in the left hind paw. Melanoma cells were obtained from malignant melanoma tumours developed in the right thigh of C57BL/6 reservoir mice. 


\subsection{Therapeutic protocol}

$A T$ treatment started at the time of tumour onset. $A T$ was obtained from certified suppliers in the local market, washed, frozen, cut into small pieces, resuspended $1 \mathrm{gr} / \mathrm{ml}$ in coconut milk containing $2 \%$ sucrose and blended 3 times in Osterizer® blender. $A T /$ coconut milk suspension was sieved through a cotton cloth, diluted $1: 3 \mathrm{v} / \mathrm{v}$ in distilled water and stored at $-20^{\circ} \mathrm{C}$ until use. Fresh $A T$ extract was provided daily on demand in $100 \mathrm{ml}$ animal dispensers. CM group received vehicle. Celecoxib was prepared $50 \mathrm{mg} / \mathrm{ml}$ in $1 \%$ carboxymethyl cellulose; $20 \mu \mathrm{l}$ was administered orally daily using a micropipette. For intratumoral application, $A T(1 \mathrm{gr} / \mathrm{ml})$ blended in distillate water were sieved and centrifuged $20 \mathrm{~min}$ at $50,000 \mathrm{~g}$, and successively filtered through 0.45 and $0.2 \mu \mathrm{m}$ cellulose filters.

\subsection{Tumorectomy}

After two weeks from macula onset, mice were subjected to amputation of the tumour paw, which it was done under general anaesthesia with pentobarbital/ketamine ( $25 \mathrm{mg} / \mathrm{kg}$ each), plus local subcutaneous lidocaine infiltration. Once amputated, $100 \mathrm{mg} / \mathrm{kg}$ dipyrone-based analgesia was injected via intraperitoneal. Physical tumour paw data were recorded, photographed and biopsied; then under aseptic and antiseptic conditions tumour mass was removed. Tumour biopsy were fixed in 10\% PBS formaldehyde $\mathrm{pH} 7.2$ and processed for haematoxylin-eosin stain.

\subsection{Autopsy}

Animals that died spontaneously, or developed thigh secondary post-surgery tumour with concomitant signs of respiratory distress were euthanized by exsanguinous, which it was done through cardiac puncture under deep anaesthesia with pentobarbital and ketamine ( $50 \mathrm{mg} / \mathrm{kg}$ each one). Organ weights and tumour staging were determined through visualization of metastases.

\subsection{Primary tumour cell viability}

Tumour mass was diluted $1: 10 \mathrm{w} / \mathrm{v}$ in physiological phosphate buffer (PPB) containing in $\mathrm{mM}$ : $\mathrm{Na}_{2} \mathrm{HPO}_{4} 5, \mathrm{NaCl}_{140}$, $\mathrm{KCl} 5, \mathrm{CaCl}_{2} 1, \mathrm{MgCl}_{2}$ 1, fluconazole 0.006, ampicillin 2.9, enrofloxacin 0.028 and glucose 5 , at $\mathrm{pH} 8$, and successively mechanically dissociated through 14,18 and $21 \mathrm{G}$ needles. Cell viability was determined by Trypan blue staining.

\subsection{Metabolic experiments}

$200 \mu \mathrm{l}$ of dissociated cells were diluted in $2 \mathrm{ml} \mathrm{PPB}$ with or without $100 \mu \mathrm{M}$ methylene blue (MB), to which $5 \mathrm{mM}$ glucose or $10 \mathrm{mM}$ lactate as energetic substrates was added. Cell suspensions were incubated at $37^{\circ} \mathrm{C}$ for 24 hours, then centrifuged at $1000 \mathrm{rpm}$ for $10 \mathrm{~min}$ and supernatant $\mathrm{pH}$ was measured. Cell pellets from samples without MB were resuspended in $2 \mathrm{ml} \mathrm{PPB}$ containing $100 \mu \mathrm{M} \mathrm{MB}$, incubated for another 1 hour at $37^{\circ} \mathrm{C}$, and then centrifuged at 2000 rpm for $10 \mathrm{~min}$ to remove supernatant. All cell precipitates containing MB, were resuspended in $1 \mathrm{ml}$ PPB plus $1 \mathrm{ml}$ of lysis buffer containing: $100 \mathrm{mM}$ tris, $100 \mathrm{mM} \mathrm{NaCl}, 50 \mathrm{mM}$ EDTA, $2 \%$ triton and $1 \%$ digitonin, vigorously stirred and incubated at $50^{\circ} \mathrm{C}$ for 24 hours, then centrifuged at $2000 \mathrm{rpm}$ for $10 \mathrm{~min}$ and supernatant OD measured at $660 \mathrm{~nm}$.

\subsection{Statistical Analysis}

All data are presented as the average \pm SEM. To establish whether there were significant differences between groups, an ANOVA followed by the Tukey post-test were performed. Macula onset time and survival curves were analysed using the Log-rank test (Mantel-Cox). DI50 was calculated by non-linear regression using four parameters dose response fitting. A p value $<0.05$ was considered statistically significant. All analyses were performed using the GraphPad Prism $4 \circledast$ program.

\subsection{Ethical Approval}

All experimental procedures performed were based in "The Bioethics and Biosafety Manual" of the National Fund for Science and Technology, Ministry of Popular Power for Science and Technology, Venezuela. The project was approved and supervised by the Bioethics Committee at the Department of Functional Sciences, School of Health Sciences, Universidad Centroccidental "Lisandro Alvarado".

\section{Results}

\subsection{Socio demographic characteristics}

25 mice (92.59 \%) developed malignant melanoma with a prepatent period ranging from 18 to 24 days, of which two mice belonging to $\mathrm{CM}$ and $\mathrm{ATCxO}$ groups, respectively, developed a rapidly infiltrating thigh inoperable tumour. 
Therefore, 23 mice underwent surgical amputation on days $14.43 \pm 2.14,15.09 \pm 1.09$ and $16.14 \pm 1.18$ after macula onset, for CM, ATO and ATCxO groups, respectively. Of these 23 mice, 6 (21.74\%; 2 from CM, 3 from ATO and 1 from ATCxO groups) died due to respiratory arrest during perioperative period. In total 17 mice survived surgery: 5 from CM, 6 from ATO and 6 from ATCxO groups. Of these, 2 mice from ATO and 1 from ATCxO groups were cured and the rest were euthanized when they developed advanced cancer. Survival time after surgery was significantly longer for ATO group when compared to CM group (see Figure 1, panels A and B). During the experimental period, mice from CM and ATO groups lost about 8 and $1.5 \%$ of their initial body weight respectively, while ATCxO showed no variation. However, body weight of ATO group showed a significantly higher weight at the time of surgery and autopsy, when compared with CM (see table 1).
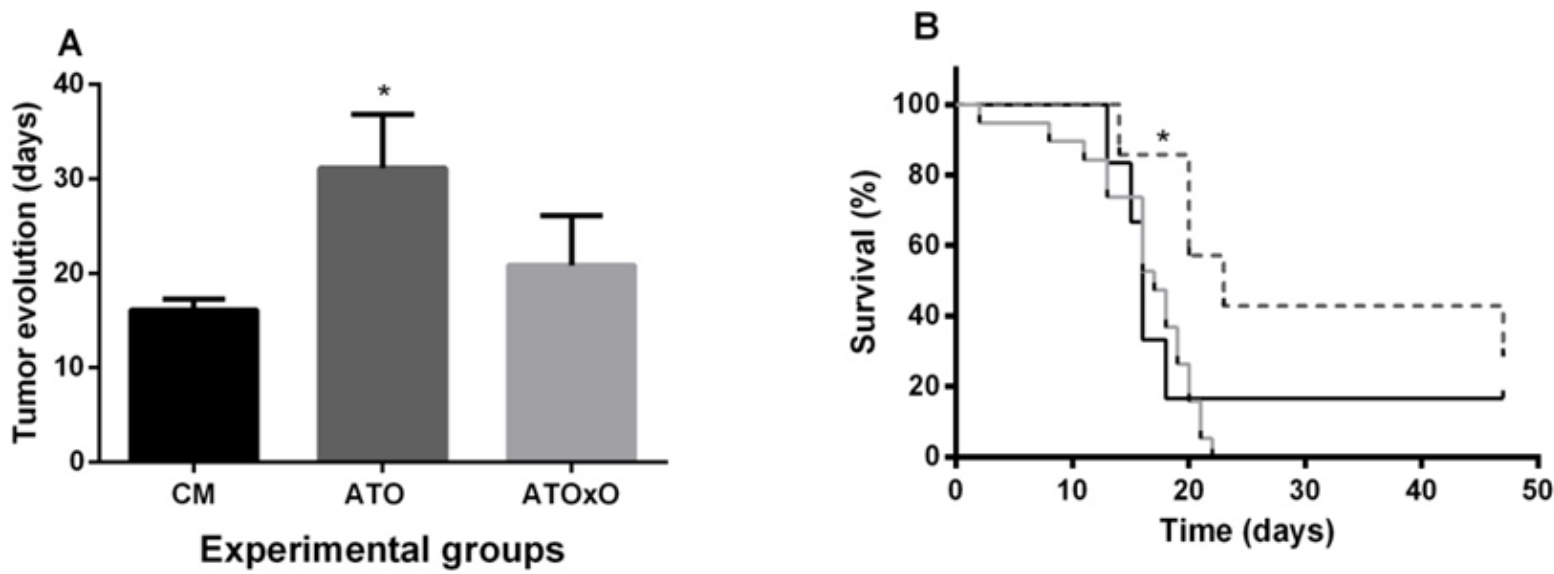

Figure 1 Disease time course and survival curves of C57BL/6 mice with malignant melanoma.

Table 1 Variations of body weight at different experimental periods.

\begin{tabular}{llll}
\hline Period & CM & AT0 & ATCx0 \\
\hline Xenograft & $24,94 \pm 0,41$ & $25,82 \pm 0,92$ & $22,60 \pm 0,37$ \\
Macula Onset & $24,14 \pm 0,74$ & $25,18 \pm 0,53$ & $24,27 \pm 0,61$ \\
Surgery & $22,54 \pm 0,40$ & $25,2 \pm 0,83^{*}$ & $23,21 \pm 0,40$ \\
Autopsy & $22,44 \pm 1,12$ & $25,44 \pm 0,71^{*}$ & $22,7 \pm 0,65$ \\
Macula-Surgery & $-1,6 \pm 0,45$ & $0,02 \pm 0,70$ & $-1,05 \pm 0,50$ \\
Surgery-Autopsy & $-0,14 \pm 1,30$ & $-0,7 \pm 0,46$ & $-0,51 \pm 0,58$ \\
Macula-Autopsy & $-1,74 \pm 1,67$ & $0,15 \pm 0,60$ & $-1,57 \pm 0,72$ \\
\hline
\end{tabular}

Values are expressed in grams. The inter-period values are the difference in weight between the early and late periods. CM: melanoma control. ATO: Allium tuberosum orally. ATCxO: Allium tuberosum celecoxib orally. $\left({ }^{*}\right)$ means $\mathrm{p}<0.05$ when compared to CM group.

\subsection{Tumour evolution and metastases}

Primary tumour evolution was progressive, in crescendo, from macula onset until surgery. At this time, CM mice showed clearly more developed primary tumours, reflected by an increased value of tumour growth variables, which had statistics significant for net and indexed volume as compared with all $A T$ treated groups, and for weight and net or indexed tumour mass as compared with ATOI group (Table 2, Figure 2 panel B). Similarly, tumour growth rate was significantly lower in $A T$ treated groups (Figure 2 panel A). 
Table 2 Weight and volumetric characteristics of primary tumor in C57BL/6 mice with malignant melanoma at surgery.

\begin{tabular}{lllll}
\hline Variable & CM & ATO & ATCx0 & ATOI \\
\hline Volume & $613,2 \pm 61,97$ & $492,4 \pm 32,8^{*}$ & $468,8 \pm 42,49 *$ & $224,6 \pm 16,8 *$ \\
Weight & $365,9 \pm 34,58$ & $296,4 \pm 41,44$ & $300,7 \pm 27,58$ & $108,7 \pm 11,96 *$ \\
Mass & $249,7 \pm 28,2$ & $177 \pm 17,57 *$ & $199,9 \pm 21,53$ & $44,00 \pm 6,47^{*}$ \\
Normalized Volume & $28 \pm 2$ & $21 \pm 1 *$ & $21 \pm 1 *$ & $10,7 \pm 1,1^{*}$ \\
Normalized Weight & $16 \pm 1$ & $11 \pm 2$ & $13 \pm 1$ & $5,173 \pm 0,68 *$ \\
Normalized Mass & $10 \pm 09$ & $6 \pm 09 *$ & $8 \pm 08$ & $2,139 \pm 0,35^{*}$
\end{tabular}

Volume unit is $\mathrm{mm}^{3}$, weight and mass units are mg. Normalization were done according corporal weight in gr. CM: control melanoma. ATO: Allium tuberosum orally. ATCxO: Allium tuberosum plus celecoxib orally. ATOI: Allium tuberosum orally and intratumoral. $\left({ }^{*}\right)$ means $\mathrm{p}<0.05$ when compared to CM group.

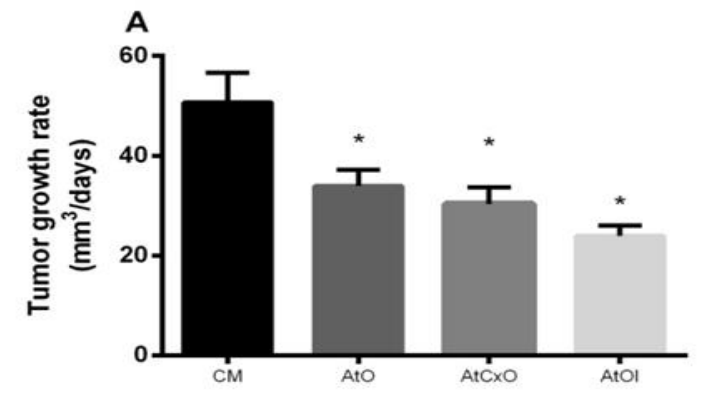

Experimental groups

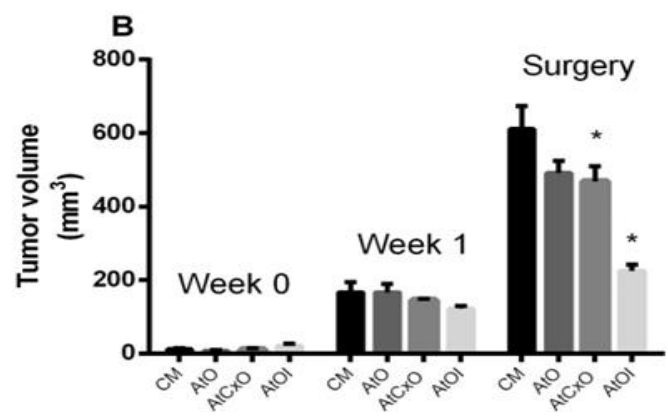

Experimental groups

Figure 2 Primary tumour evolution in C57BL/6 mice.

In Figure 3 we show macroscopic pathological characteristics of the primary tumour. In panel A, Bl6-F10 malignant melanoma typical macroscopic characteristics are displayed; note that tumor infiltrates the entire paw, reaching a 10 mm diameter, acquiring a rounded shape with an active crusty ulcerative plantar center. In panel B, a primary tumor belonging to ATO group is shown; tumor volume and ulcerated plantar area are slightly smaller and non-ulcerated violaceous areas with nodular infiltrates can be seen. In image $\mathrm{C}$, tumor belonging to ATCxO group is displayed, observe that ulcero-crusted region occupies a smaller area and a primary tumor of smaller volume has whitish areas suggestive of necrosis. In image D, tumor from ATOI group is shown, where practically no tumor infiltration but a residual crusted ulcer region and thumb amputation can be observed.

A

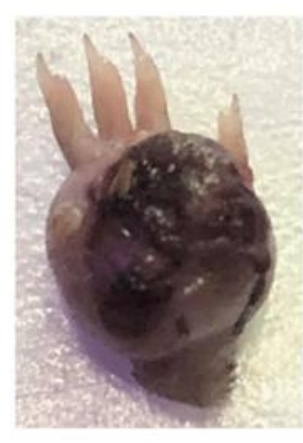

B

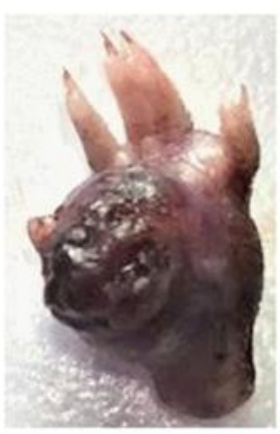

C

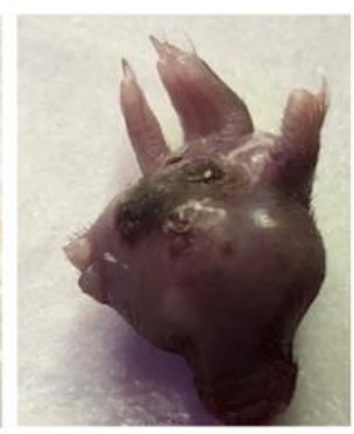

D

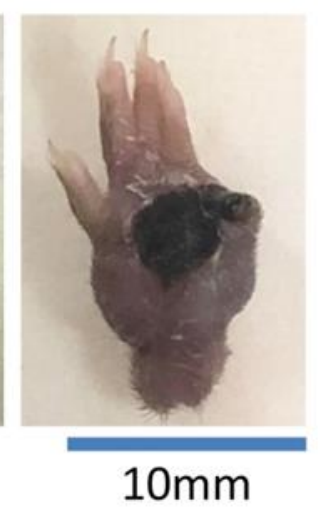

Figure 3 Macroscopic pathological characteristics of the primary tumour in mice from different experimental groups. 
In figure 4, we show the microscopic pathological characteristics of the primary tumour. Image A comes from a tumour of CM group, where typical characteristics of malignant melanoma B16F10 can be seen; for example, a homogeneous tissue, composed by epithelioid fusiform cells, with amphophilic cytoplasm, containing rounded nuclei with several nucleoli; no inflammatory cell infiltration or fibrosis can be seen. Images B and C come from primary tumours from ATO and ATOI mice, respectively; note in B there are islands of degenerating melanoma cells infiltrated by inflammatory cells surrounded by areas of fibrosis; while $\mathrm{C}$ shows extensive necrotic areas with mononuclear infiltrate, incipient fibrosis and virtually no melanoma cells.

A

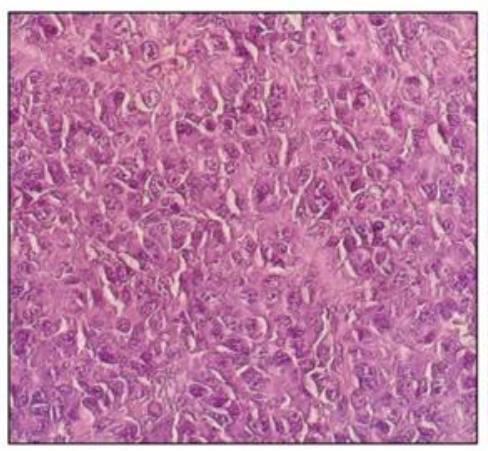

B

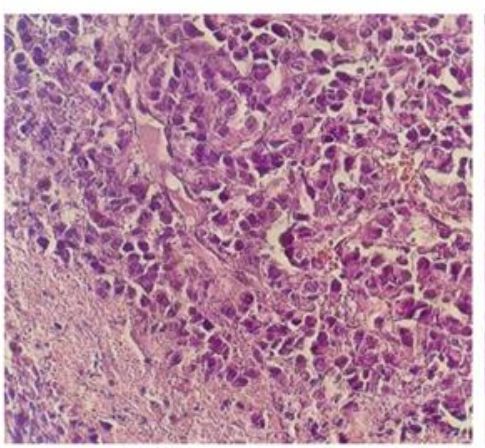

C

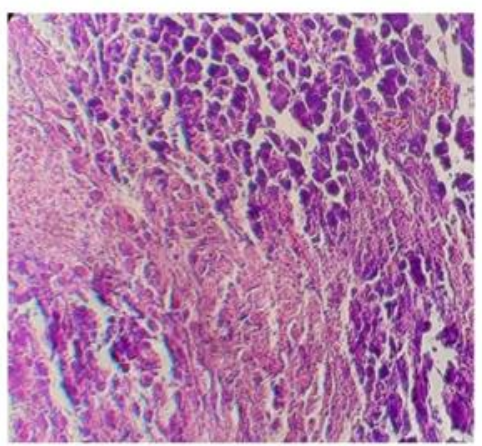

Figure 4 Microscopic pathological characteristics of the primary malignant melanoma tumours.

Trypan blue cell analysis of the primary tumour masses showed a cell density between 232 and 241 x $10^{6}$ cells/gr of tissue. Non-viable fusiform granular cells represented in average between 52 and $58 \%$ of the cells; non-viable rounded cells without defined nucleus (ghost cells) with apoptotic characteristics represented between 42 and $49 \%$, while bright and clear viable cells with morphological characteristics of active cancer cells represented between 1 and $2 \%$, of which between 0.08 and $0.28 \%$ were in mitosis. Analyses of cell populations showed no statistically significant differences between experimental groups (see Table 3).

Table 3 Cellularity of the primary tumor mass.

\begin{tabular}{|c|c|c|c|c|c|c|}
\hline \multirow{2}{*}{ Cells } & \multicolumn{2}{|l|}{$\mathbf{C M}$} & \multicolumn{2}{|l|}{ ATO } & \multicolumn{2}{|l|}{ ATCxO } \\
\hline & $\mathrm{n} \times 10^{6}$ cells $/ \mathrm{gr}$ & $\%$ & $\mathrm{n} \times 10^{6}$ cells $/ \mathrm{gr}$ & $\%$ & $\mathrm{n} \times 10^{6}$ cells $/ \mathrm{gr}$ & $\%$ \\
\hline Total & $235,7 \pm 29,13$ & 100 & $231,6 \pm 29,10$ & $231,6 \pm 29,1$ & $241,1 \pm 23,54$ & $241,1 \pm 23,54$ \\
\hline$\%$ Viable & $5,58 \pm 3,75$ & $0,72 \pm 0,25$ & $5,65 \pm 1,81$ & $1,72 \pm 0,50$ & $4,39 \pm 1,37$ & $1,68 \pm 0,47$ \\
\hline$\%$ Mitosis & $0,78 \pm 0,59$ & $0,28 \pm 0,21$ & $0,42 \pm 0,17$ & $0,19 \pm 0,10$ & $0,21 \pm 0,11$ & $0,08 \pm 0,04$ \\
\hline$\%$ Ghost & $5,58 \pm 3,75$ & $47,85 \pm 8,11$ & $5,65 \pm 1,81$ & $41,59 \pm 3,06$ & $4,39 \pm 1,37$ & $46,34 \pm 4,99$ \\
\hline$\%$ Granular & $130,4 \pm 36,42$ & $52,15 \pm 8,11$ & $116,7 \pm 17,71$ & $58,41 \pm 3,06$ & $131,8 \pm 21,81$ & $53,66 \pm 4,98$ \\
\hline
\end{tabular}

Of the 17 mice undergoing amputation that survived the surgery, the number of mice that developed infiltrating tumor metastasis to homolateral thigh were 14 (82\%), of which 5 belonged to CM, 4 to ATO and 5 to AtCxO groups. The analysis of the mice that developed infiltrating popliteal thigh masses showed that secondary tumour weights did not display statistical differences.

The lymph node metastases were observed to ipsilateral popliteal and inguinal node, as well as to para-aortic nodes. $100 \%$ of the mice from CM group developed metastases to these nodes, compared to $25 \%$ and $80 \%$ observed in ATO and ATCxO groups, respectively (Table 4). CM showed metastatic lungs in $3(60 \%)$, ATO in $3(60 \%)$ and ATCxO in 1 (20\%) mice. The organs weight assessment showed no significant differences between experimental groups (Table 5). 
Table 4 Lymphatic nodes characteristics in C57BL/6 mice with malignant melanoma at autopsy.

\begin{tabular}{|c|c|c|c|c|c|c|c|c|c|}
\hline \multirow{3}{*}{ Node } & \multicolumn{3}{|c|}{ CM } & \multicolumn{3}{|c|}{ ATO } & \multicolumn{3}{|c|}{ ATCxO } \\
\hline & \multicolumn{2}{|c|}{ Tumour like } & \multirow{2}{*}{$\begin{array}{l}\text { Weight } \\
\text { Mean } \pm \text { SEM }\end{array}$} & \multicolumn{2}{|c|}{$\begin{array}{l}\text { Tumour } \\
\text { like }\end{array}$} & \multirow{2}{*}{$\begin{array}{l}\text { Weight } \\
\text { Mean } \pm \text { SEM }\end{array}$} & \multicolumn{2}{|c|}{$\begin{array}{l}\text { Tumour } \\
\text { like }\end{array}$} & \multirow{2}{*}{$\begin{array}{l}\text { Weight } \\
\text { Mean } \pm \text { SEM }\end{array}$} \\
\hline & $\mathrm{n}$ & $\%$ & & $\mathrm{~N}$ & $\%$ & & $\mathrm{n}$ & $\%$ & \\
\hline LPN & 5 & 100 & $4905 \pm 838,8$ & 4 & 100 & $5716 \pm 278$ & 5 & 100 & $4811 \pm 795$ \\
\hline LIN & 5 & 100 & $1232 \pm 547,6$ & 1 & 25 & $101,0 \pm 52,21$ & 4 & 80 & $435,0 \pm 132,9$ \\
\hline RIN & 0 & 0 & $8,33 \pm 0,88$ & 0 & 0 & $34,0 \pm 22,01$ & 0 & 0 & $10,0 \pm 1,53$ \\
\hline PAN & 0 & 0 & $13,5 \pm 4,48$ & 0 & 0 & $40,0 \pm 13,02$ & 1 & 25 & $40,0 \pm 20,43$ \\
\hline
\end{tabular}

CM: Control Melanoma; ATO: Allium tuberosum orally. ATCxO: Allium tuberosum celecoxib orally; LPG: left popliteal ganglia; LIN: left inguinal node; RIN: right inguinal node; PAN: para aortic node; weight expressed in mg.

Table 5 Weights of different organs obtained from C57BL/6 mice with malignant melanoma at autopsy.

\begin{tabular}{llll}
\hline Organ & CM & ATO & ATCxO \\
\hline LPN & $3517 \pm 1067$ & $5716 \pm 278$ & $4016 \pm 1027$ \\
RIN & $8,13 \pm 1,0$ & $34 \pm 22,01$ & $9,98 \pm 1,54$ \\
LIN & $1232 \pm 547,6$ & $101,0 \pm 52,21$ & $435,0 \pm 132,9$ \\
PAN & $31,68 \pm 16,96$ & $32 \pm 14,53$ & $39,96 \pm 20,46$ \\
Spleen & $152 \pm 20,63$ & $172,4 \pm 26,8$ & $154 \pm 25,24$ \\
Liver & $1099 \pm 86,31$ & $1326 \pm 75,35$ & $1134 \pm 130,2$ \\
Heart & $128,7 \pm 12,83$ & $119 \pm 10,67$ & $114,8 \pm 9,282$ \\
Thymus & $67,50 \pm 14,82$ & $52,6 \pm 8,244$ & $316,7 \pm 130,7^{*}$ \\
Lung & $212,6 \pm 29,43$ & $200,6 \pm 24,81$ & $179 \pm 8,745$ \\
\hline
\end{tabular}

Weight expressed in mg. LPN: left popliteal node. RIN: right inguinal node. LIN: left inguinal node. PAN: para aortic nodes. CM: melanoma control. ATO: Allium tuberosum orally. ATCxO: Allium tuberosum Celecoxib orally. $\left({ }^{*}\right)$ means $\mathrm{p}<0.05$ when compared to the control group.

\subsection{Anaerobic metabolism and dose response curve}

Anaerobic glycolytic activity measured through $\mathrm{H}^{+1}$ production was higher in $\mathrm{CM}$ either in presence or absence of $\mathrm{MB}$, being significant as compared with $\mathrm{ATCxO}$ group in presence of $\mathrm{MB}$. Cellular redox activity using glucose as the energy substrate and measured as oxidized MB showed that ATO tumour cells had significantly lower levels of oxidized MB at 48 hours of incubation as compared with CM tumour cells. Residual reductive capacity, measured as the difference between MB concentrations at 48 hours compared to 24 hours, showed that ATO tumour cells had significant decreased levels of oxidized MB at 48 hours, indicating a greater residual redox capacity, while in melanoma cells from CM and ATCxO tumours the levels of oxidized MB were increased at this time (Table VI).

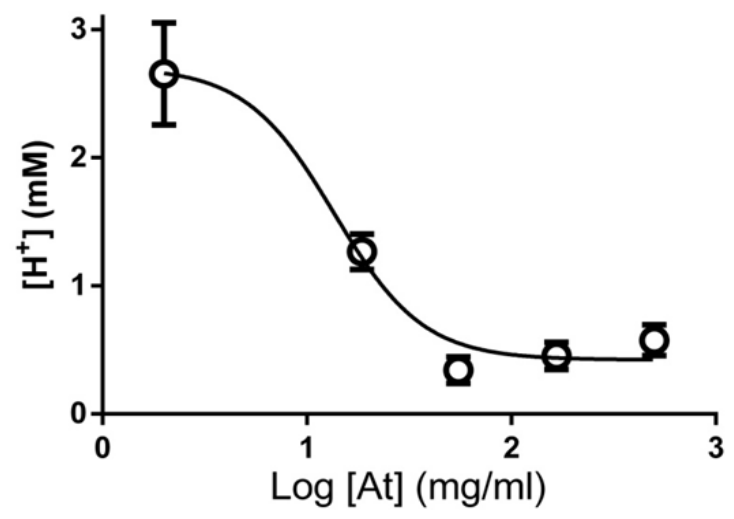

Figure 5 Dose response curve related to tumour anaerobic metabolism. 
Likewise, cellular redox activity using lactate as the energy substrate, showed similar results to those obtained using glucose, observing that ATO tumour cells showed greater reductive capacity at 48 hours, without reaching statistical significance (Table 6). Finally, when testing in vitro the activity of increasing doses of $A T$ extract on anaerobic metabolism of melanoma cells, we observed that $A T$ decreased $\mathrm{H}^{+}$production in a dose-dependent manner with an $\mathrm{IC}_{50}$ of $1.13 \mathrm{mg} / \mathrm{ml}$ (Figure 5).

Table 6 Anaerobic metabolism and redox capacity of malignant melanoma cells having as substrate glucose or lactate.

\begin{tabular}{|c|c|c|c|c|c|}
\hline $\begin{array}{l}\text { Metabolic } \\
\text { Test }\end{array}$ & Substrate & $\begin{array}{l}\text { Incubation } \\
\text { Time (hrs) }\end{array}$ & $\mathrm{CM}$ & ATO & ATCxO \\
\hline \multirow{4}{*}{$\begin{array}{l}\text { Acidification } \\
\text { Capacity } \\
\left(\mu \mathrm{mol} \text { of } \mathrm{H}^{+}\right)\end{array}$} & Glucose & 24 & $2,00 \pm 0,56$ & $1,28 \pm 0,36$ & $0,93 \pm 0,29$ \\
\hline & Glucose MB & 24 & $1,45 \pm 0,38$ & $0,72 \pm 0,17$ & $0,52 \pm 0,15^{*}$ \\
\hline & & 24 & $2,28 \pm 0,32$ & $2,73 \pm 0,32$ & $1,88 \pm 0,10$ \\
\hline & Glucose & 48 & $3,52 \pm 0,37$ & $2,02 \pm 0,38^{*}$ & $2,95 \pm 0,20$ \\
\hline \multirow{4}{*}{$\begin{array}{l}\text { Redox } \\
\text { Capacity } \\
\left(\text { nmol of } \mathrm{MB}^{+}\right)\end{array}$} & & $\Delta_{(48-24)}$ & $1,23 \pm 0,44$ & $-0,71 \pm 0,61^{*}$ & $1,07 \pm 0,16$ \\
\hline & & 24 & $2,35 \pm 0,36$ & $2,57 \pm 0,35$ & $1,82 \pm 0,10$ \\
\hline & Lactate & 48 & $3,27 \pm 0,44$ & $2,56 \pm 0,38$ & $3,28 \pm 0,15$ \\
\hline & & $\Delta_{(48-24)}$ & $0,92 \pm 0,71$ & $-0,01 \pm 0,63$ & $1,45 \pm 0,13$ \\
\hline
\end{tabular}

\section{Discussion}

In the present work, we show that aqueous extract of $A T$ has a curative therapeutic effect on B16F10 malignant melanoma in C57BL/6 mice, by slowing tumour growth and by inducing tumour necrosis. This effect was more evident with an intratumoral administration and it was corroborated in experiments in vitro where AT totally inhibited anaerobic metabolism.

To our knowledge, only two works have explored chemopreventive effect of $A T$ in vivo [8,11]. In one, the effect of $A T$ was controversial, because lung metastases were prevented by $40 \%$ trough oral administration, but on the contrary, intravenous extract administration was devoided of effect [11]. In the other, similar as it is shown in the present paper, $A T$ extracts increased survival of mice transplanted with sarcoma [8], confirming antitumor activity of $A T$.

Theoretically, achieved AT systemic concentrations in the present work were 33 and $35 \mathrm{mg} / \mathrm{ml}$ for orally and intratumoral-orally administered extracts respectively, however, into the tumour interstice, concentrations could have reached around $100 \mathrm{mg} / \mathrm{ml}$ after local application. In vitro, the IC50 obtained was $9.59 \mathrm{mg} / \mathrm{ml}$, reaching maximum efficacy between 37 and $100 \mathrm{mg} / \mathrm{ml}$, which is in concordance with results obtained in vivo, especially with intratumoral administration. Working in vitro, in two murine and four human cancer cell lines Shao et al (2001)(11) showed quite similar results, with $\mathrm{IC}_{50}$ for cell proliferation inhibition between 2,5 to $13 \mathrm{mg} / \mathrm{ml}$; they also observed that higher doses induced apoptosis after cells were exposed to AT for 4-6 hours. Moreover, working in vivo with Bl6-F10 melanoma in $\mathrm{C} 57 \mathrm{BL} / 6$ mice, they reported that intravenous injection of the extract (1.25 or $6.25 \mathrm{mg} / \mathrm{gr}$ ) did not show any effect, these doses could have been lower than systemic concentration achieved in the present paper. Therefore, translating these to the present paper, intratumoral administration of cytotoxic apoptotic dose could have caused tumoral cell dead before diffusing systematically; these reasoning suggests that cytotoxic doses against melanoma cells should be between 50 to $100 \mathrm{mg} / \mathrm{gr}$.

Cytotoxicity of tumour cells caused by $A T$ has been related to thiosulfinates, which inhibited cell proliferation and activated both caspase dependent and independent apoptotic pathways $[8,9,10]$. In the present work, we observe that intratumoral administration of $A T$ aqueous extracts induced tumour necrosis and activated a strong inflammatory response with fibrosis (see figure 4). 
The relationship between necrosis and cancer progression is controversial, the presence of intratumoral necrosis has been related to a worse prognosis [13]. However, recently it has been observed, in renal cell carcinoma with low degree of malignancy, that extensive necrosis predicts a good evolution and prognosis [14]. Similarly, in patients with rectal cancer, necrosis response was associated with longer recurrence-free survival, overall survival, and lower perineural and vascular tumour invasion [15].

The effect of $A T$ on mechanisms involved in carcinogenesis has been poorly studied. One mechanism linked to carcinogenesis is tumorigenic inflammation, which allows the production of pro-inflammatory trophic factors, favouring tumour cell proliferation and free radicals production [16]. Free radicals feedback the inflammatory process and induce tumour cell mutations favouring clonal selectivity, leading to increasingly metabolically autonomous cells with high proliferative, evasive and metastatic capacity [17]. AT extract has an anti-inflammatory effect, because it has been reported in human umbilical vein endothelial cells stimulated by TNF- $\alpha$, that $A T$ reduced intercellular and vascular

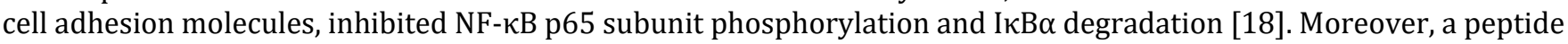
purified from Chinese leek, efficiently quench free radicals and protected human foetal hepatocyte cell lines against hydrogen peroxide-induced damage [19]. Translating this knowledge to data provided here, we suggest that AT could decrease free radicals induce-inflammation and mutagénesis, therefore, it could decrease melanoma cell proliferation, promoting apoptosis.

AT antitumor activity could depend on substances found in Allium genus, just like organosulfur compounds: methyl allyl disulfide and diallyl disulfide [20]. These organosulfur molecules have immune stimulant effects, which could be responsible of anticancer effects of these molecules. In this sense, it has been reported that diallyl disulfide antagonized the effect of linoleic acid (LA), a potent breast cancer cell stimulator and synergized the effect of eicosapentaenoic acid (EPA), a suppressor in human breast cancer cell lines [21].

In the present paper, we observe that tumour cells from mice treated with AT preserved for a longer time their capacity to reduce methylene blue under restrictive culture conditions, having either glucose or lactate as metabolic substrates. These results could indicate an interesting issue, regarding AT promoted oxidative substrate catabolism through Krebs's cycle. It is widely reported that aerobic metabolism decreases tumorigenic and invasive properties of cancer cells; on the contrary, malignancy is related to metabolic reprograming to anaerobic glucose metabolism, rendering lactate as product, a phenomenon classically call Warburg's effect [22]. Cancer cells with aerobic metabolism tend to be more differentiated, less proliferative, and more susceptible to anticancer drugs.

\section{Conclusion}

In conclusion, we present data demonstrating that $A T$ aqueous extract had cytotoxic curative effect on melanoma B16F10 in C57BL/6 mice, an effect related to the dose and route of administration. Likewise, AT extract decreased anaerobic metabolism and increased reductive capacity of cancer cells in vitro, indicating that $A T$ counteracts Warburg's effect, which favors glucose and lactate aerobic metabolism decreasing cancer cells malignancy. Because of these properties, $A T$ deserves special attention for future clinical trials, both in preventive or as an adjuvant in therapeutic protocols.

\section{Compliance with ethical standards}

\section{Acknowledgments}

The research was carried out in the context of a "Training Program for Young Scientific Talents" sponsored by the Scientific, Humanistic and Technological Development Council at Universidad Centroccidental "Lisandro Alvarado", Barquisimeto, Venezuela. The beneficiary students partially financed their projects.

\section{Disclosure of conflict of interest}

The authors do not disclose any conflict of interest.

\section{Statement of ethical approval}

All experimental procedures performed were based in "The Bioethics and Biosafety Manual" of the National Fund for Science and Technology, Ministry of Popular Power for Science and Technology, Venezuela. The project was approved and supervised by the Bioethics Committee at the Department of Functional Sciences, School of Health Sciences, Universidad Centroccidental "Lisandro Alvarado". 


\section{References}

[1] Kozovska Z, Gabrisova V and Kucerova L. (2016). Malignant melanoma: diagnosis, treatment and cancer stem cells. Neoplasma, 63(4), 510-7.

[2] Alvarez E. B16 murine melanoma. In Tumor models in cancer research, Ed. Teicher BA, Humana Press, Totowa New Yersey (USA), 4, 73-92.

[3] Chen ST, Geller AC and Tsao H. (2013). Update on the epidemiology of melanoma. Curr Dermatol Rep, 2 (1), 2434.

[4] Desai AG, Qazi GN, Ganju RK, El-Tamer M, Singh J, Saxena AK, Bedi YS, Taneja SC and Bhat HK. (2008). Medicinal plants and cancer chemoprevention. Curr Drug Metab, 9(7), 581-591.

[5] Kuruppu AI, Paranagama P and Goonasekarac CL. (2019). Medicinal plants commonly used against cancer in traditional medicine formulae in Sri Lanka. Saudi Pharm J, 27(4), 565-573.

[6] Asemani Y, Zamani N and Bayat M. (2019). Amirghofran Z. Allium vegetables for possible future of cancer treatment. Phytother Res, 33(12), 3019-3039.

[7] Lawthienchai N, Asavasanti S, Tongprasan T and Yasurin P. (2016). Chemical profile and bioactivity of Chinese chives (Allium tuberosum Rottl. Ex Spreng) crude extracts under different solvent extractions. Int J Adv Biotechnol Res, 7(4), 2209-2221

[8] Lee JH, Yang HS, Park KW, Kim JY, Lee MK, Jeong IY, Shim KH, Kim YS, Yamada K and Seo KI. (2009). Mechanisms of thiosulfinates from Allium tuberosum L.-induced apoptosis in HT-29 human colon cancer cells. Toxicol Lett, 188(2), 142-7.

[9] Kim SY, Park KW, Kim JY, Jeong IY, Byun MW, Park JE, Yee ST, Kim KH, Rhim JS, Yamada K and Seo KI. (2008). Thiosulfinates from Allium tuberosum L. induce apoptosis via caspase-dependent and independent pathways in PC-3 human prostate cancer cells. Bioorg Med Chem Lett, 18(1), 199-204.

[10] Park KW, Kim SY, Jeong IY, Byun MW, Park KH, Yamada K and Seo KI. (2007). Cytotoxic and antitumor activities of thiosulfinates from Allium tuberosum L. J Agric Food Chem, 55(19), 7957-61.

[11] Lam YW, Wang HX and Ng TB. (2000). A robust cysteine-deficient chitinase-like antifungal protein from inner shoots of the edible chive Allium tuberosum. Biochem Biophys Res Commun, 279(1), 74-80.

[12] Shao J, Dai J and Ma JK. (2001). A pilot study on anticancer activities of Chinese leek. J Altern Complement Med, $7(5), 517-22$.

[13] Karsch-Bluman A, Feiglin A, Arbib E, Stern T, Shoval H, Schwob O, Berger M and Benny O. (2019). Tissue necrosis and its role in cancer progression. Oncogene, 38(11), 1920-1935.

[14] Collins J and Epstein JI. (2017). Prognostic significance of extensive necrosis in renal cell carcinoma. Hum Pathol, 66, 108-114.

[15] Jung JH, An HJ, Kim HJ, Lee J, Lee KM, Kim SH, Cho HM and Shim BY. (2016). Evaluation of treatment response and tissue necrosis as prognostic indicators following neoadjuvant chemoradiotherapy in rectal cancer patients. Korean J Intern Med, 31(1), 134-44.

[16] Jinushi M. (2014). Role of cancer stem cell-associated inflammation in creating pro-inflammatory tumorigenic microenvironments. Oncoimmunology, 3, e28862.

[17] Ríos-Arrabal S, Artacho-Cordón F, León J, Román-Marinetto E, Del Mar Salinas-Asensio M, Calvente I and Núñez MI. (2013). Involvement of free radicals in breast cancer. Springerplus, 2, 404.

[18] Hur HJ and Lee AS. (2017). Protective Effect of Allium tuberosum Extract on Vascular Inflammation in Tumor Necrosis Factor- $\alpha$-induced Human Vascular Endothelial Cells. J Cancer Prev, 22(4), 228-233.

[19] Hong J, Chen T, Hu P, Yang J and Wang S. (2014). Purification and characterization of an antioxidant peptide (GSQ) from Chinese leek (Allium tuberosum Rottler) seeds. J Funct Foods, 10, 144-153.

[20] Yang Y, Su Q, Shi L, Chen G, Zeng Y, Shi C and Zhang Y. (2019). Electrophysiological and behavioral responses of Bradysia odoriphaga (Diptera: Sciaridae) to volatiles from its Host Plant, Chinese Chives (Allium tuberosum Rottler ex Spreng). J Econ Entomol, 112(4), 1638-1644.

[21] Venkatesh YP. (2018). Immunomodulatory Attributes of Aged Garlic Extract and Its Components. In Immunotoxicology, Immunopathology, and Immunotherapy, 1(14), 203-224. 
[22] Schwartz L, Supuran CT and Alfarouk KO. (2017). The Warburg Effect and the Hallmarks of Cancer. Anticancer Agents Med Chem, 17(2), 164-17.

\section{How to cite this article}

Corvaia-Bolívar MC, González-Barrios AC, Colmenárez-Rojas AA, Pulido-Barreras SP, Suárez-Rodríguez MA and Bonfante-Cabarcas RA. (2020). Allium tuberosum aqueous extract had curative effects on malignant melanoma in C57BL/6 mice. World Journal of Advanced Research and Reviews, 7(1), 07-17. 